\title{
Technology for developing the professional competence of physical education teachers in architecture and construction university
}

\author{
Ruslan Garifullin ${ }^{1 *[0000-0001-9182-0474]}$, Rais Imangulov ${ }^{10000-0003-3158-8815]}$, Evgeniy \\ Arkhipov ${ }^{1[0000-0002-5604-7153]}$, Naila Ishmukhametova ${ }^{1[0000-0003-4256-4368]}$, and Ravil Nabiullin ${ }^{2}$
}

${ }^{1}$ Kazan State University of Architecture and Engineering, 420043, Zelenaya st., Kazan, Russia ${ }^{2}$ Volga State University of Physical Culture, Sports and Tourism, 420010, the Universiade Village, Kazan, Russia

\begin{abstract}
The objective of this paper is to investigate the possibility of forming the professional competence of physical education teachers in a university of architecture and engineering. At the beginning of the experiment the baseline level of teachers' professional competence was determined in order to form the control and experimental groups among them. In the control group the formation of competence of teachers was carried out by taking professional development courses according to the «standard» program, according to which the participants were given lectures, seminars on various modules of the program, having to complete a course with a final qualifying paper on a selected topic. Teachers in the experimental group were trained according to the professional development programme, taking into account the developed model of competence formation. At the end of the training the previously studied indicators were tested in both groups and the data obtained was then compared. As a result, it was found that the professional competence level of teachers in the experimental group increased significantly compared to this in the control group. Thus, it showed that to be able to form teachers' professional competence «standard» professional development programmes currently implemented by Kazan State University of Architecture and Engineering are not enough. For effective formation of competence it is necessary to have a special technology of teachers' training, which is implemented in the developed pedagogical model of formation of teachers' professional competence.
\end{abstract}

Keywords: teacher, physical education, professional competence development, pedagogical conditions, pedagogical model, training.

\section{Introduction}

Implementation of modern requirements of the Federal State Educational Standards (FSES) in the system of higher education obliges scientific and pedagogical workers to improve

\footnotetext{
${ }^{*}$ Corresponding author : rus-garifullin@yandex.ru
} 
and search for new approaches to the organization of the educational process, to the system of quality control of teachers and students, to the methods of teaching educational material and organization of independent work. To a greater extent, these issues have affected the discipline «Physical Education and Sports», which, according to FSES, is included in the basic part of the curricula of all areas of training, but it is significantly different from other disciplines, both in the content and in the methodological aspect [1-2].

Analyzing the problems arising in the implementation of modern requirements of FSES, preliminary research in the form of questionnaires, surveys, and interviews with physical education teachers were conducted. As a result of preliminary research, it was established that one of the main problems in the implementation of modern requirements of FSES is the low level of competence of teaching staff and coaches and lack of motivation among them to improve it [3-5].

This statement is confirmed by questionnaires and surveys of students on the quality of physical education (PE) teaching at universities, which are reflected in the following results: ineffective methodology of teaching PE or its complete absence, when after the warm-up part of the lesson students are actually «left to themselves»; lack of interest of students in both academic and independent exercises in PE (according to survey results, passivity and unwillingness to do PE is observed in 55-60\% of the cases).

At the same time, the problems of low efficiency of the existing state programme of physical education may be observed in universities in general, which is confirmed by extensive resources [6-9] and is expressed in steady dynamics of increase of student morbidity from the first year to the end of training, unsatisfactory material and technical base of universities, poor physical fitness of students, etc.

Unfortunately, surveys have shown that some teachers do not think that the «blame» for students' negative attitude towards physical education classes lies not only in the shortcomings of the effectiveness of the physical education state programme at universities, but also in the quality of teaching, which is directly linked to the competence of teachers of physical education, while the others are categorically unwilling to understand this.

In this regard, research into the possibility of forming competence in the field of teaching is an urgent issue to resolve.

\section{Materials and methods}

Theoretical methods included analysis and synthesis of scientific and methodological resources, theoretical modelling, interpretation. Empirical methods comprised study and generalization of advanced pedagogical experience, survey-diagnostic methods (questioning, interviewing, conversations), expert evaluation, observation, pedagogical experiment, and mathematical processing of research results.

The study was conducted in natural conditions during 2016-2018 on the basis of Kazan State University of Architecture and Engineering. The study involved 30 teachers of the Department of Physical Education and Sports and the coaching staff.

The experiment was organised as follows:

- at the first stage we studied scientific and methodological literature on the problem of research, determined the tools and methodology of the study;

- at the second stage, taking into account the analysis of the literature, we developed a model for the formation of professional competence of physical education teachers in architecture and engineering higher education institution;

- at the third stage we conducted experimental research on the formation of teachers' professional competence, taking into account the application of the developed model, analyzed the data obtained and formulated conclusions on the results of the work. 


\section{Results and discussion}

The analysis of literature sources [10-11], as well as the survey of teachers in the Department of Physical Education and Sports has revealed that the use of traditional approaches in enhancing the competences of physical education teachers is ineffective. In particular, a widespread method for enhancing teachers' competences is the completion of a professional development programme; this approach is also applied at Kazan State University of Architecture and Engineering. Every year, physical education teachers undergo the professional development course at the university in order to enhance their professional competencies. Usually, as per the «standard» professional development programme, the trainee teachers are given lectures and seminars on different modules of the programme, which each thainee should complete with a final qualifying paper on a selected topic and defend it to address the certification committee. After successful defence of the work a trainee teacher receives the certificate, which suggests that the objectives of the programme are achieved and the physical education teacher has raised his/her professional competence to a relatively high level. However, numerous tests and surveys conducted among teachers who participated in these «standard» programmes reveal their ineffectiveness. In particular, depending on different conditions of the professional development programmes, the competence of the trainees and teachers of the programme, the material and technical base, etc., the increase in the professional competence of the course participants was in the range of $5-15 \%$.

In this connection, at the second stage of the work we conducted a theoretical research on the creation of an effective pedagogical model of professional competence formation of teachers at architecture and engineering higher education institution. The developed model is a complex pedagogical process, which includes objective, content, organizational and technological blocks, result of modelling with competence formation levels (high, medium, low) and pedagogical conditions of model effective functioning. The developed pedagogical model of formation of teachers' professional competence is shown in Figure 1.

The objective is to form professional competence of physical education teachers. The content block defines the main components of professional competence: personal, cognitive, activity-performance, reflexive. The personal competence contains the level of motivation, professionally important qualities of a teacher's personality. Cognitive competence determines his/her ability to learn. Reflexive competence reflects the teacher's self-assessment. Activity-performance competence contains the knowledge and skills of a teacher applied in professional activities. Organisational block includes forms, methods and means of achieving the main goal, which should correspond to the current level of pedagogical technologies development and be selected taking into account professional abilities of teachers.

The technological block determines the sequence of stages, through which the formation of professional competence is ensured. The result of modelling is the formed professional competence with the levels of its formation. The levels of professional competence formation are determined by the following criteria - low, medium and high.

It should be noted that before training, according to this model, a diagnostic stage is carried out, which includes the identification of weaknesses and gaps in teachers' knowledge, their willingness and ability to learn. In the next stage, based on the results obtained, the methods and forms of the technological stage (training stage) are determined and only then the training process itself is carried out. In addition, during the learning process, according to the developed pedagogical model, teachers should be engaged in self-education on additional issues of the professional development programme.

The following pedagogical conditions are important aspects of the effective functioning of the model. The first condition includes creating a motivational pedagogical environment 
and encouraging teachers to improve their skills and self-education. The second condition is the construction of individual educational trajectories of teachers improving their competence, which includes: an individual approach to each student; the opportunity to master the level and content of education that meets their capabilities and interests; training with the use of modern pedagogical technologies. The third condition is ensured by the availability of good facilities and infrastructure for the learning process.

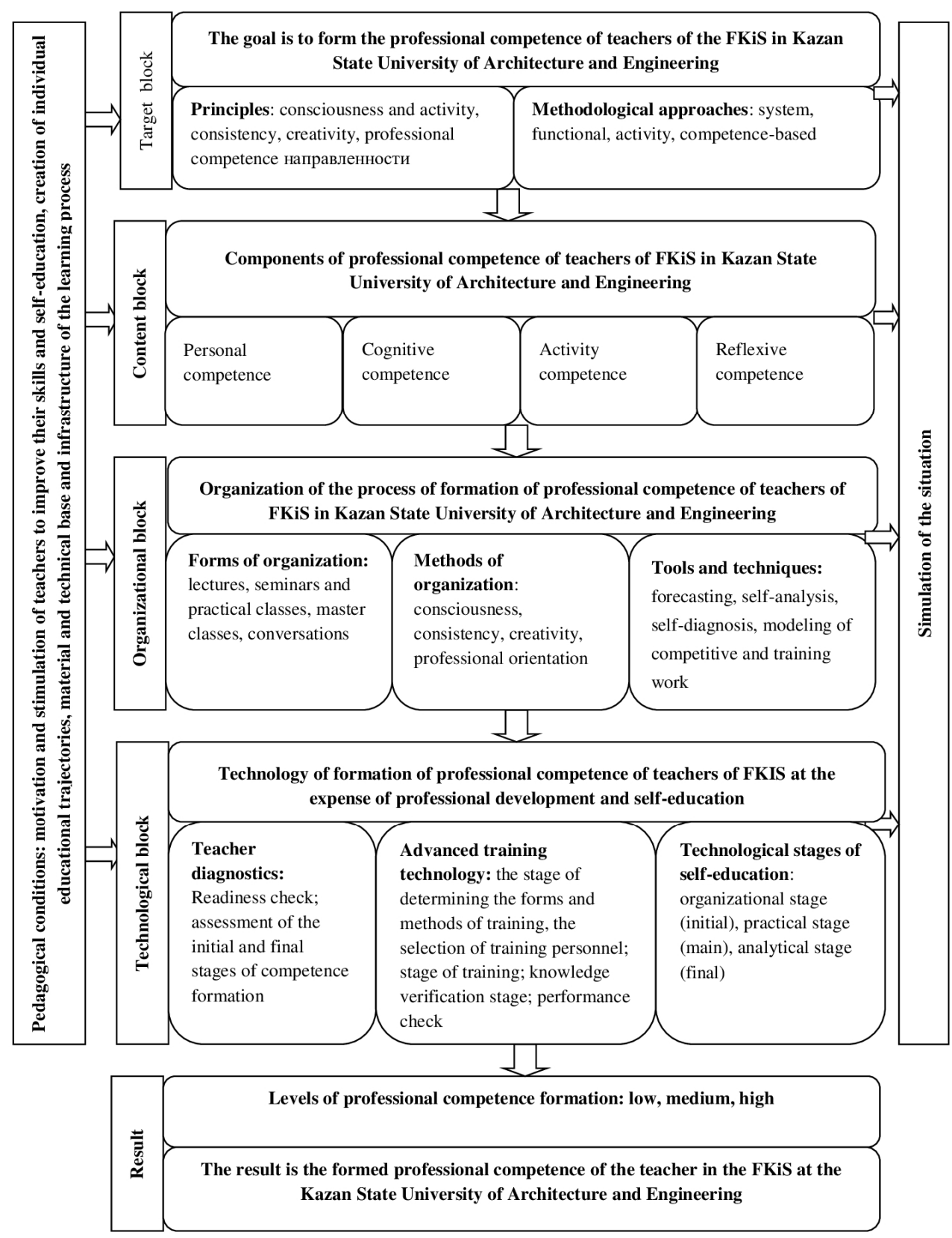

Fig. 1. Pedagogical model of formation of the professional competence development of physical education teachers. 
In the third stage, taking into consideration the developed pedagogical model, the professional competence formation of 30 teachers and coaches at Kazan State University of Architecture and Engineering was investigated. For this purpose, at the beginning of the experiment the initial level of teachers' professional competence was determined and they formed the control and experimental groups of 15 people in each. The teachers were divided into groups based on their qualifications so that the groups could be «equal».

Then, during the academic year, according to the plan of the department, the teachers of both groups underwent professional development under the programme «Modern approaches and innovative technologies in the work of physical education teachers and coaches». In the control group, the training was carried out according to the «standard» programme, the technology of which was described above. The teachers of the experimental group were trained according to the specified professional development programme, taking into account the developed model of professional competence formation. At the end of the training we repeatedly determined the previously studied professional competence indicators of teachers in the control and experimental groups and compared the data obtained.

To determine the initial and final levels of professional competence of teachers and coaches we used the method of expert evaluation. The experts were the specialists who conducted professional development programme. The expert assessment included comprehensive testing of teachers on all components of professional competence. The results of the compared groups for all components of professional competence were summed and presented in the form of the average value of total professional competence.

The results of expert evaluation on the level of professional competence of teachers and coaches of control (CG) and experimental groups (EG) before and after the experiment in percentage ratio are shown in Table 1 and Table 2.

Table 1. Results of expert assessment on the level of professional competence of teachers of CG $(n=15)$ and $E G(n=15)$ before the experiment, \%

\begin{tabular}{|l|l|l|l|l|l|l|}
\hline \multirow{2}{*}{\begin{tabular}{c}
\multirow{2}{*}{$\begin{array}{c}\text { Components } \\
\text { competences }\end{array}$} \\
\cline { 2 - 8 }
\end{tabular}} & \multicolumn{3}{|c|}{ Level of professional competence before the experiment } \\
\cline { 2 - 8 } & CG & EG & CG & EG & CG & EG \\
\hline Personal & 22.2 & 25.3 & 38.4 & 36.2 & 39.4 & 38.5 \\
\hline Cognitive & 14.6 & 15.8 & 57.3 & 61.5 & 28.1 & 22.7 \\
\hline Activity-effective & 16.8 & 16.1 & 23.2 & 21.6 & 60.0 & 62.3 \\
\hline Reflexive & 38.5 & 37.4 & 23.5 & 23.5 & 38.0 & 39.1 \\
\hline $\begin{array}{l}\text { General } \\
\text { competence } \\
(\mathrm{M} \pm \mathrm{m})\end{array}$ & $23.0 \pm 2.8$ & $23.7 \pm 2.9$ & $35.6 \pm 3.3$ & $35.7 \pm 3.3$ & $41.4 \pm 3.8$ & $40.6 \pm 3.7$ \\
\hline
\end{tabular}

Table 2. Results of expert assessment on the level of professional competence of teachers of CG $(\mathrm{n}=15)$ and $\mathrm{EG}(\mathrm{n}=15)$ after the experiment, \%

\begin{tabular}{|l|l|l|l|l|l|l|}
\hline \multirow{2}{*}{\begin{tabular}{c}
\multirow{2}{*}{$\begin{array}{c}\text { Components of } \\
\text { competences }\end{array}$} \\
\cline { 2 - 8 }
\end{tabular}} & \multicolumn{3}{|c|}{ Level of professional competence after the experiment } \\
\cline { 2 - 8 } & CG & EG & CG & EG & CG & EG \\
\hline Personal & 28.1 & 47.1 & 45.5 & 32.6 & 26.4 & 20.3 \\
\hline Cognitive & 19.9 & 19.3 & 58.4 & 67.1 & 21.7 & 13.6 \\
\hline Activity-effective & 21.7 & 49.2 & 33.7 & 38.4 & 44.6 & 12.4 \\
\hline Reflexive & 40.2 & 39.4 & 29.4 & 44.5 & 30.4 & 16.1 \\
\hline $\begin{array}{l}\text { General } \\
\text { competence } \\
(\mathrm{M} \pm \mathrm{m})\end{array}$ & $27.5 \pm 2.9$ & $38.8 \pm 3.4$ & $41.7 \pm 3.8$ & $45.6 \pm 3.9$ & $30.8 \pm 3.0$ & $15.6 \pm 1.9$ \\
\hline
\end{tabular}


The results of the competence components were presented as an average value of general professional competence and compared the data in the groups obtained before and after the experiment for each level of professional competence. For each pair of compared groups (CG and EG) the Fisher's criterion was calculated, which allowed to assess the reliability of differences between them. The significance level of the empirical value of Fisher's criterion was determined by a special table. The greater the value of Fisher's criterion, the more likely it is that the differences in the compared attribute are reliable. The results are presented in Table 3 and Figure 2.

Table 3. The result of comparison the professional competence of teachers EG ( $n=15)$ and $K G(n=15)$ before and after the experiment, taking into account the Fisher criterion, \%.

\begin{tabular}{|c|c|c|c|c|c|c|}
\hline \multirow[b]{3}{*}{$\begin{array}{c}\text { Compared } \\
\text { groups }\end{array}$} & \multicolumn{6}{|c|}{ Level of professional competence } \\
\hline & \multicolumn{2}{|c|}{ high } & \multicolumn{2}{|c|}{ average } & \multicolumn{2}{|c|}{ low } \\
\hline & 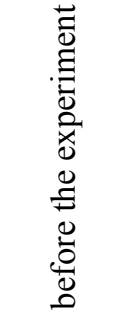 & 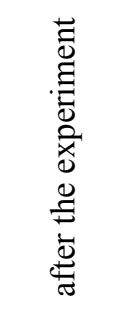 & 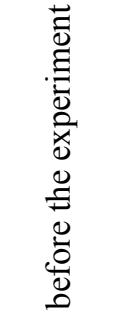 & 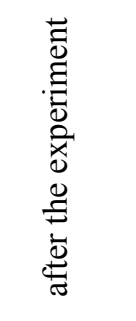 & 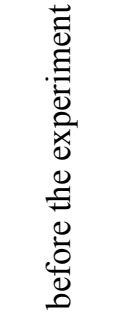 & 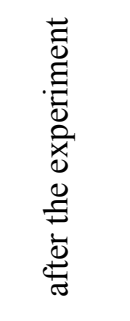 \\
\hline $\begin{array}{l}\mathrm{EG}, \\
(\mathrm{M} \pm \mathrm{m})\end{array}$ & $23.7 \pm 2.9$ & $38.8 \pm 3.4$ & $35.7 \pm 3.3$ & $45.6 \pm 3.9$ & $40.6 \pm 3.7$ & $15.6 \pm 1.9$ \\
\hline $\begin{array}{l}\mathrm{KG}, \\
(\mathrm{M} \pm \mathrm{m})\end{array}$ & $23.0 \pm 2.8$ & $27.5 \pm 2.9$ & $35.6 \pm 3.3$ & $41.7 \pm 3.8$ & $41.4 \pm 3.8$ & $30.8 \pm 3.0$ \\
\hline $\begin{array}{l}\text { The value } \\
\text { of the } \\
\text { Fisher } \\
\text { criterion }\end{array}$ & 0.05 & $1.85^{*}$ & 0.01 & $0.82 *$ & 0.07 & $2.75 * *$ \\
\hline
\end{tabular}

Note: $*_{-}$reliably at $(\mathrm{P}<0.05) ; *^{*}$ - reliably at $(\mathrm{P}<0.01)$.

The data presented in Table 3 and Figure 2 show that before the experiment, there is no significant difference between the values obtained in the compared CG and EG in all levels of professional competence, Fisher's criterion for them is less than 0.1. This fact indicates the correctness of the choice of CG and EG in the preparatory stage of the experiment.

The results of comparing the values obtained in CG and EG after the experiment indicate significant differences on each level of professional competence, which is confirmed by significant values of Fisher's Criterion. In particular, Fisher's Criterion for the level of high professional competence was 1.85; for the medium level it was 0.82 ; for the low level it was 2.75 .

At the same time, the percentage of teachers with «high» professional competence increased by $11.3 \%$ in the EG in comparison with the CG; with the «medium» level it rose by $3.9 \%$. These changes occurred due to a decrease in the percentage of teachers with «low» professional competence level. In particular, after the experiment the percentage of teachers with «low» level of competence in the EG decreased by $14.8 \%$ as compared to the CG.

Thus, it was found that the professional competence level of teachers in the EG compared to the CG significantly increased by conducting training under the professional development programme, taking into account the proposed pedagogical model. 


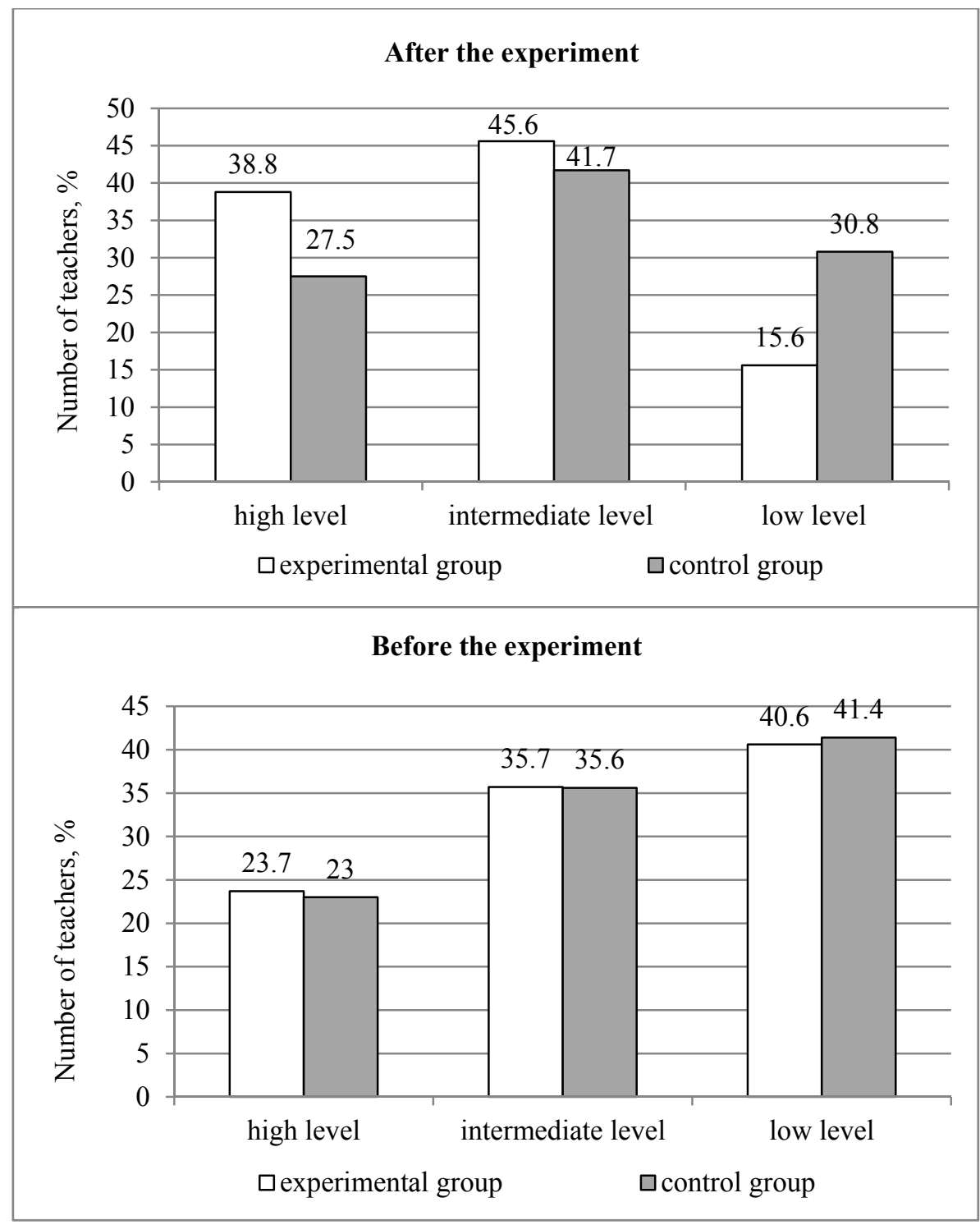

Fig. 2. Result of comparison of professional competence of teachers in the EG and CG before and after the experiment using Fisher's criterion, \%.

\section{CONCLUSION}

As a result of the conducted research it was found out that in order to form effectively professional competence of teachers and coaches «standard» professional development programmes implemented at present in Kazan State University of Architecture and Engineering are not enough. When implementing professional development programmes it is necessary to have a special training technology, which is implemented in the developed pedagogical model of professional competence formation for teachers and trainers. In this model the process of professional competence formation of teachers is considered a 
continuous educational stage, which includes the construction of interrelated blocks: objective, content, organizational and technological block; result of modelling with the levels of competence formation (high, medium, low) and pedagogical conditions of effective model functioning.

\section{References}

1. R. Khuzhin, A. Greb, Physical education service contribution to technical university graduate's professional competitiveness, Theory and Practice of Physical Culture, 4, 12 (2019)

2. D. Nasibullina, T. Nasibullin, N. Krasulina, Individual academic physical education programs for special health groups for physical progress, Teoriya i Praktika Fizicheskoy Kultury, 4, 54-56 (2019)

3. V. Yu. Lebedinsky, O. I. Kuzmina, M. D. Kudryavtsev, V. I. Gruzenkin, T. G. Arutunian, Health monitoring of students of the III functional group for controlling and designing educational environment (physical education) in a non-sport university. Human Sport Medicine, 19(4), 78-91 (2019) DOI: 10.14529/hsm190410

4. A. V. Dorontsev, A. A. Svetlichinkina, N. A. Zinchuk, Example of physical training health activities after total hip replacement with Wright implant, Advances in gerontology, 32(1-2), 207-210 (2019)

5. N. K. Gafiatulina, L. I. Makadey, I. V. Gluzman, A. D Lozhechkina, L. A. Volkova, A. $\mathrm{P}$. Bandurin, The role of health-saving technologies in the process of students educational and professional socialization, EurAsian Journal of BioSciences, 13(2), 1557-1563 (2019)

6. V. Filonenko, M. Nikulina, E. Patrakov, O. Kovtun, Social representation about health and health preservation in young students, Sotsiologicheskie Issledovaniya, 7, 152-157, (2018)

7. E. Mugattarova, A. Bolotnikov, R. Garifullin, R. Imangulov, V. Kalmanovich, R. Khairullin, Development of health-saving environment at engineering university, IOP conference series: Materials Science and Engineering, 890, 012172 (2020) DOI: 10.1088/1757-899X/890/1/012172

8. V. Panachev, L. Zelenin, A. Opletin, A. Legotkin, R. Kusekova, Aspects of healthimproving and sports-mass work students, Journal of Global Pharma Technology, 10(5), 268-273 (2018)

9. L. Akshayaa, V. Vishnupriya, R. Gayathri, Awareness of chronic fatigue syndrome among the college students - a survey, Drug Invention Today, 11(6), 1369-1371 (2019)

10. J. Shi, J. Shen, J. Xie, J. Zhi, Y. Xu Chronic fatigue syndrome in Chinese middle-school students, Medicine (United States), 97(4), 9716 (2018)

11. Yu. Nagornyak, T. Kanakina, V. Fokin, Study of syndrome of emotional burnout in students of the faculty of pharmacy, Health Care of the Russian Federation, 62, 254-258 (2018)

12. S. Griggs, Hope and mental health in young adult college students: An integrative review, Journal of Psychosocial Nursing and Mental Health Services, 55(2), 28-35 (2017)

13. J. Breedvelt, Y. Amanvermez, M. Harrer, E. Karyotaki, S. Gilbody, C. Bockting, P. Cuijpers, D. Ebert, The effects of meditation, yoga, and mindfulness on depression, anxiety, and stress in tertiary education students, A meta-analysis Frontiers in Psychiatry, 10(APR), 193 (2019)

14. V. Kuchma, L. Sukhareva, I. Rapoport, E. Shubochkina, N. Skoblina, O. Milushkina, Population health of children, risks to health and sanitary and epidemiological 
wellbeing of students: Problems, ways of solution and technology of the activity, Gigiena i Sanitariya, 96(10), 990-995 (2017)

15. O. Kokun, Y. Imas, A. Vovkohon, V. Potop, G. Korobeynikov, L. Korobeynikova, A. Gorashchenco, Polevaya-Secaryanu, Physical education and sports as a tool for formation of students' psychophysiological readiness to their professional work, Journal of Physical Education and Sport, 18(2) 143, 966-971 (2018)

16. D. Savelyev, V. Kuvanov, E. Zherlygina, Implementation of the online format of training sessions on physical culture in the conditions of the university, Theory and Practice of Physical Culture, 3, 15 (2020)

17. T. Shutova, L. Andryushchenko, I. Orlan, N. Ryzhkin, Digital approach in the organization of physical culture and sports at the university, Theory and practice of Physical Culture, 3, 12 (2021)

18. L. Pashchenko, O. Krasnikova, Influence of motor mode on physical health of university students, Teoriya i Praktika Fizicheskoy Kultury, 6, 24-26 (2017)

19. B. Butzer, M. Ebert, S. Telles, S. Khalsa, School-based Yoga Programs in the United States: A Survey, Advances in mind-body medicine, 29(4), 18-26 (2015)

20. V. Irhin, I. Irhina, I. Nikulin, University sports and recreation activities system as a factor of ensuring the students health, World Journal of Medical Sciences, 9(3), 162$166(2013)$

21. F. Ishkineeva, K. Ozerova, S. Ahmetova, A. Kaveeva, Students healthy lifestyle and the strategy of adaptation to the university environment, International Journal of Innovative Technology and Exploring Engineering, 9(1), 5123-5126 (2019)

22. E. Yakimova, P. Terehov, O. Salnikova, N. Ishmuhametova, Crowdsourcing as an approach to solving environmental problems by future construction engineers, IOP Conference Series: Materials Science and Engineering, 890(1), 012174 (2020) DOI:10.1088/1757-899X/890/1/012174 